\title{
Erratum: 'Flowing' under the radar in a multifaceted liquid reality: The ekerk narrative
}

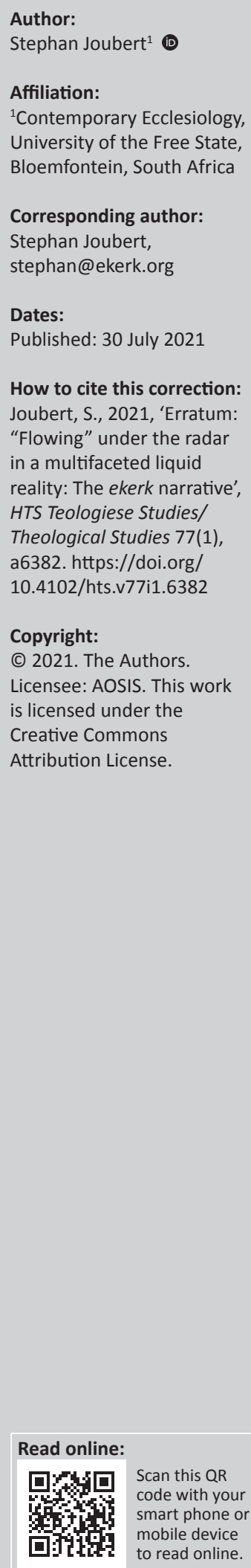

In the version of this article published earlier, Joubert, S., 2018, "“Flowing" under the radar in a multifaceted liquid reality: The ekerk narrative', HTS Teologiese Studies/Theological Studies 74(3), 4966. https://doi.org/10.4102/hts.v74i3.4966, the ORCID of the author was given incorrectly. The correct ORCID should be https://orcid.org/0000-0002-0550-182X instead of https://orcid. org/0000-0003-2942-6606 in the 'Author' section.

This correction does not alter the study's findings of significance or overall interpretation of the study results. The publisher apologises for any inconvenience caused. 